\title{
Use of ultrasonic extraction in determining apparent digestibility in fish feed
}

\author{
Bruna Cavecci ${ }^{1}$ - Paula Monteiro de Lima ${ }^{2}$ - José Cavalcante Souza Vieira ${ }^{1}$. \\ Camila Pereira Braga ${ }^{1}$ - João Vitor de Queiroz ${ }^{2}$ Alis Correia Bittarello ${ }^{2}$. \\ Pedro Magalhães de Padilha ${ }^{1}$
}

Received: 12 December 2014/Accepted: 20 July 2015/Published online: 24 July 2015

(C) Springer Science+Business Media New York 2015

\begin{abstract}
The feeds supplied to farmed fish should be rich in protein and minerals, such as animal protein, but more expensive alternatives comprising vegetable protein have emerged in recent years. However, the minerals essential to the proper development of fish must be assessed. To determine whether the minerals supplied in the diet are being fully exploited, the equation of the apparent digestibility coefficient is typically used with an external marker such as chromium. Moreover, the concentrations of the metals of interest are usually obtained using an acid digestion in the digester block; however, this digestion is harmful to both the analyst and the environment. An alternative to this digestion is described in this work. Four types of feeds were made with different types of protein substitutes.
\end{abstract}

Keywords Oreochromis niloticus $\cdot$ Nutrients $\cdot$ Extraction of minerals $\cdot$ Aquaculture

\section{Introduction}

Aquaculture has grown more rapidly worldwide than any other sector of animal production. In 2006, FAO data [1] showed that this increase in production, including that of

Bruna Cavecci

brucavecci@gmail.com

1 Present Address: Department of Chemistry and Biochemistry, Institute of Bioscience, São Paulo State University (UNESP), Rubião Junior District, Botucatu, São Paulo 18618-970, Brazil

2 College of Veterinary and Animal Science, São Paulo State University, Botucatu, São Paulo, Brazil fish, crustaceans, and molluscs, was only $3.9 \%$ in 1970 but $33.0 \%$ in 2005.

The growth of the sector has been accompanied by increased demand for feed [2]. Thus, the development of ingredients that promote technological and sustainable fish production without compromising production performance will be a priority in the future [3].

The replacement of certain agro-industry products and by-products as ingredients in fish diets by other products as yeast, turnip meal, and pinion tame, was spurred by studies on the nutrient digestibility of these foods; this replacement has also been presented as an economically viable alternative to using agro-industry products $[4,5]$.

We use the so-called fecal indicators to determine the digestibility of fish feed. Chromium (III) oxide $\left(\mathrm{Cr}_{2} \mathrm{O}_{3}\right)$ is the most widely used indicator in studies on digestibility. It is completely indigestible, non-absorbable, and has no pharmacological effect on, and passes freely through, the digestive tract. The percentage of $\mathrm{Cr}_{2} \mathrm{O}_{3}$ in fish feces and in the initially mixed diet can be compared; the coefficient of total or partial digestibility of the nutrients metabolized can then be estimated on the basis of this comparison $[6,7]$.

As such, this study aimed to develop a new methodology that enables the safe measurement of inorganic nutrients and chromium (III) oxide, and comparisons were made with conventional methodology.

\section{Materials and methods}

\section{Samples}

Samples of fish feeds were developed by the Fish Nutrition Laboratory of the Faculty of Veterinary Medicine and Animal Science/UNESP-Botucatu (Aquanutri) and formulated from 
four different sources: yeast full, autolyzed yeast, turnip meal, and pinion tame.

In diets containing whole yeast, autolyzed yeast, bran turnip, and jatropha, the base diet were replaced by 30,25 , and $10 \%$, respectively, of the test ingredient (Table 1). Furthermore, $0.10 \% \mathrm{Cr}_{2} \mathrm{O}_{3}$ was added as the external indicator [8].

A total of 100 juvenile Nile Tilapia (Oreochromis niloticus) with average weight of $100 \pm 12 \mathrm{~g}$ were housed in circular cages (ten fish per cage), made of plastic mesh (1.50 cm mesh). Each cage was housed in a circular $250 \mathrm{~L}$ power aquarium. During the day, the fish were kept in power aquariums, where they fed at will from 8:00 to 17:00; they fed more often in the afternoon than in the morning. After the feeding step, the fish were transferred to fiberglass $300 \mathrm{~L}$ feces collection tanks (tank by a cage). A $200 \mathrm{~mL}$ vial $\log$ of clear vinyl (for feces) was tightly coupled to the conically shaped bottom of each tank. The fish were kept in these tanks until the following morning, and then returned to the power aquariums to start a new cycle. This procedure allowed the collection of feces, without contamination from the feed diet. After the cages were removed, the feces suspended in water were decanted and collected in flask cylinders. Each aquarium was then cleaned in preparation for a second (repeat) test. In each test, the feces were collected over a period of 6 days.

\section{Sample preparation}

The feed and feces samples were dried in a forced-air oven at $50{ }^{\circ} \mathrm{C}$ for approximately $48 \mathrm{~h}$ crushed with pestle porcelain crucibles, and fractionated with a sieve to obtain homogeneous granules.

\section{Extraction of minerals by acid digestion}

Approximately $100 \mathrm{mg}$ of each food and feces sample was weighed; three samples of each type of feed and feces were prepared. This mass was packed in filter paper and transferred to Kjeldahl flasks to which were added about 3 and $2 \mathrm{~mL}$ of nitric acid and hydrogen peroxide (both pa Merck), respectively, were added. Samples containing oxidizing compounds appeared white on the filter paper.

The Kjeldahl flasks were placed in the block digestor, which was heated to a temperature of approximately $110{ }^{\circ} \mathrm{C}$. The entire procedure was performed in a gas exhaust hood until the organic material was completely consumed. After adequate cooling, the acid extracts were transferred to volumetric flasks; diets containing added yeast were transferred to flasks containing $50 \mathrm{~mL}$ of distilled/deionized water; those containing radish and jatropha seed meal were transferred to flasks containing $25 \mathrm{~mL}$ of distilled/deionized water and homogenized dilute acid extract.
Table 1 Formulation and chemical composition of the experimental diets (in natural matter)

\begin{tabular}{llllll}
\hline Ingredients & Feed 1 & Feed 2 & Feed 3 & Feed 4 & Feed 5 \\
\hline Albumin & 32.00 & 22.40 & 22.40 & 24.40 & 30.30 \\
Gelatin & 7.70 & 5.39 & 5.39 & 6.39 & 6.39 \\
Corn starch & 44.58 & 31.18 & 31.18 & 32.68 & 40.68 \\
Cellulose & 6.00 & 4.20 & 4.20 & 4.20 & 4.20 \\
Antioxidant (BHT) & 0.02 & 0.01 & 0.01 & 0.01 & 0.01 \\
Soybean oil & 6.00 & 4.20 & 4.20 & 4.70 & 5.80 \\
Dicalcium phosphate & 3.00 & 2.10 & 2.10 & 2.10 & 2.10 \\
Common salt (NaCl) & 0.10 & 0.07 & 0.07 & 0.07 & 0.07 \\
Vitamin supplement & 0.50 & 0.35 & 0.35 & 0.35 & 0.35 \\
Yeast full & - & 30.00 & - & - & - \\
Autolyzed yeast & - & - & 30.00 & - & - \\
Bran turnip & - & - & - & 25.00 & - \\
Bran jatropha & - & - & - & - & 10.00 \\
Chromium oxide & 0.10 & 0.10 & 0.10 & 0.10 & 0.10 \\
Total & $100.00 \%$ & $100.00 \%$ & $100.00 \%$ & $100.00 \%$ & $100.00 \%$ \\
\hline
\end{tabular}

Feed 1 feed reference, Feed 2 feed with $30 \%$ yeast integrity, Feed 3 feed with $30 \%$ autolyzed yeast, Feed 4 feed with $25 \%$ bran turnip, feed with $10 \%$ jatropha, BHT butyl hydroxy toluene, Vitamin supplementation assurance levels per kg of product Vit. A IU-1200,000; Vit. D3-200,000 UI; Vit. E-12,000 mg; vit. K3-2400 mg; vit. B1-4800 mg; vit. B2-4800 mg; vit. B6-4000 mg; vit. B12-4800 mg; 1200 mg-folic acid; pantothenate Ca- 12,000 mg; vit. C-48,000 mg; biotin, $48 \mathrm{mg}$; hill-65,000 mg; niacin-24,000 mg 


\section{Extraction of minerals by ultrasound}

Approximately $100 \mathrm{mg}$ of samples of biological materials (feed or fish feces), previously prepared as described above, were transferred to $20 \mathrm{~mL}$ Teflon bottles. Aliquots of $10 \mathrm{~mL}$ of $0.10 \mathrm{~mol} \mathrm{~L}^{-1}$ hydrochloric acid solution were then added to the bottles. The mixtures (sample/acid solution) were then ultrasonically agitated in order to extract the analytes. Various agitation times and ultrasonic power were used in order to determine the effectiveness of this extraction method.

\section{Determination of minerals}

An atomic absorption spectrometer (Shimadzu AA-6800 model) was used to determine the concentrations of calcium, copper, iron, manganese, and zinc in the samples. The equipment was operated under the conditions described in the manual provided by the manufacturer [9]. In addition, the concentration of phosphorus was determined by using the spectrophotometric method of colorimetric acid [10].

\section{Determination of the concentration of chromic oxide in the samples of feed and feces}

The concentration of chromium oxide in each sample was determined (external label) via the sampling and quantification of the suspension by GFAAS. This was done by first sonicating the suspension in order to obtain a homogeneous suspension. The homogeneous suspension was then injected directly into the graphite tube of the atomic absorption spectrometer, whose inner wall was previously covered with metallic palladium. This methodology prevents the mineralization, which gives rise to the extremely toxic nitric/perchloric dichromate ions [11].

\section{Determination of digestibility coefficients}

We used Eq. (1) [12-14] to calculate the apparent digestibility coefficient (Da) of nutrients in the diet of the juvenile Nile Tilapia.

$\mathrm{Da}=100-\left[100-\left[\frac{\% \mathrm{Cr}_{2} \mathrm{O}_{3 \mathrm{r}}}{\% \mathrm{Cr}_{2} \mathrm{O}_{3 \mathrm{f}}}\right] \times\left[\frac{\% \mathrm{~N}_{\mathrm{f}}}{\% \mathrm{~N}_{\mathrm{r}}}\right]\right]$

$\mathrm{Da}$ is the apparent digestibility, $\% \mathrm{Cr}_{2} \mathrm{O}_{3 \mathrm{r}}$ the percentage of chromium oxide in the feed, $\% \mathrm{Cr}_{2} \mathrm{O}_{3 \mathrm{f}}$ the percentage of chromium oxide in feces, $\% \mathrm{~N}_{\mathrm{r}}$ the nutrient percentage in the diet, $\% \mathrm{~N}_{\mathrm{f}}$ the percentage nutrient in the feces, values of Da were calculated using the results obtained from extraction methods, which include acid mineralization and ultrasonic agitation, respectively.

\section{Results and discussion}

The efficiency of the extraction process of the sample feed and fish feces was evaluated by varying the extraction time and ultrasonic power. In fact, five 40-s cycles of ultrasonic agitation at $40 \%$ of the maximum working power $(136 \mathrm{~W})$ resulted in the best absorbance signals, as measured by GFAAS or FAAS; the concentrations of $\mathrm{Ca}, \mathrm{Cu}, \mathrm{Fe}, \mathrm{Mn}$, and $\mathrm{Zn}$ were determined. The concentration of $\mathrm{P}$ was determined via ultraviolet (UV)-Visible spectroscopy.

Table 2 Concentration of calcium, copper, iron, manganese, zinc, and phosphorus in the feed samples, feces, and standard certificate, as obtained from using acid digestion in the extraction process

\begin{tabular}{lllllll}
\hline Samples & $\mathrm{Ca}(\%)$ & $\mathrm{Cu}(\%)$ & $\mathrm{Fe}(\%)$ & $\mathrm{Mn}(\%)$ & $\mathrm{Zn}(\%)$ & $\mathrm{P}(\%)$ \\
\hline Feed 1 & $1.80 \pm 0.003$ & $0.003 \pm 4 \times 10^{-5}$ & $0.04 \pm 5 \times 10^{-3}$ & $0.005 \pm 8 \times 10^{-5}$ & $0.02 \pm 2 \times 10^{-4}$ & $1.50 \pm 0.02$ \\
Feed 2 & $5.40 \pm 0.07$ & $0.005 \pm 6 \times 10^{-5}$ & $0.11 \pm 6 \times 10^{-3}$ & $0.09 \pm 1 \times 10^{-3}$ & $0.03 \pm 4 \times 10^{-4}$ & $3.10 \pm 0.03$ \\
Feed 3 & $5.60 \pm 0.06$ & $0.005 \pm 7 \times 10^{-5}$ & $0.08 \pm 910^{-4}$ & $0.08 \pm 9 \times 10^{-4}$ & $0.03 \pm 5 \times 10^{-4}$ & $3.00 \pm 0.03$ \\
Feed 4 & $1.61 \pm 0,04$ & $0.002 \pm 2.10^{-5}$ & $0.06 \pm 7 \times 10^{-4}$ & $0.05 \pm 6 \times 10^{-4}$ & $0.02 \pm 3 \times 10^{-4}$ & $1.53 \pm 0.03$ \\
Feed 5 & $1.24 \pm 0.03$ & $0.003 \pm 4 \times 10^{-5}$ & $0.03 \pm 4 \times 10^{-4}$ & $0.02 \pm 3 \times 10^{-4}$ & $0.04 \pm 5 \times 10^{-4}$ & $1.01 \pm 0.02$ \\
Feces 1 & $1.84 \pm 0.02$ & $0.002 \pm 1 \times 10^{-5}$ & $0.03 \pm 4 \times 10^{-3}$ & $0.004 \pm 5 \times 10^{-5}$ & $0.02 \pm 3 \times 10^{-4}$ & $1.40 \pm 0.01$ \\
Feces 2 & $6.90 \pm 0.19$ & $0.004 \pm 5 \times 10^{-5}$ & $0.09 \pm 8 \times 10^{-4}$ & $0.07 \pm 8 \times 10^{-4}$ & $0.01 \pm 2 \times 10^{-4}$ & $3.16 \pm 0.04$ \\
Feces 3 & $6.30 \pm 0.21$ & $0.003 \pm 2 \times 10^{-5}$ & $0.06 \pm 9 \times 10^{-4}$ & $0.06 \pm 8 \times 10^{-4}$ & $0.04 \pm 6 \times 10^{-4}$ & $3.12 \pm 0.04$ \\
Feces 4 & $1.91 \pm 0.05$ & $0.003 \pm 4 \times 10^{-5}$ & $0.07 \pm 8 \times 10^{-4}$ & $0.06 \pm 8 \times 10^{-4}$ & $0.03 \pm 5 \times 10^{-4}$ & $1.81 \pm 0.04$ \\
Feces 5 & $1.41 \pm 0.04$ & $0.004 \pm 5 \times 10^{-5}$ & $0.02 \pm 3 \times 10^{-4}$ & $0.01 \pm 2 \times 10^{-4}$ & $0.03 \pm 4 \times 10^{-4}$ & $1.21 \pm 0.03$ \\
RM 1548a & $0.18 \pm 9 \times 10^{-3}$ & $2.26 \pm 0.05$ & $0.0029 \pm 8 \times 10^{-5}$ & $0.0005 \pm 1 \times 10^{-5}$ & $0.0021 \pm 8 \times 10^{-5}$ & $0.32 \pm 5.10^{-3}$
\end{tabular}

Feed 1 feed reference, Feed 2 feed with $30 \%$ yeast integrity, Feed 3 feed with $30 \%$ autolyzed yeast, Feed 4 feed with $25 \%$ bran turnip, Feed with $10 \%$ jatropha, Feces 1 fish fed base diet, Feces 2 fish fed diets containing whole yeast, Feces 3 fish fed diets containing autolyzed yeast, Feces 4 fish fed diets containing $25 \%$ turnip bran, Feces 5 fish fed diets containing $10 \%$ jatropha

\# Standard certificate containing: Ca-0.19 $\pm 0.01(\%) ; 2.32 \pm 0.16-\mathrm{Cu}\left(\mathrm{mg} \mathrm{kg}^{-1}\right)$; Fe-0.0035 $\pm 4.10^{-4}(5) ; 0.0006 \pm 1.7 .10^{-5}-\mathrm{Mn}(\%)$; $\mathrm{Zn}-$ $0.0024 \pm 1.8 .10^{-4} ; \mathrm{P}-0.35 \pm 0.02$ 
Table 3 Concentration of calcium, copper, iron, manganese, zinc, and phosphorus in the feed samples, feces, and standard certificate, as obtained from using ultrasonic agitation in the extraction process

\begin{tabular}{lllllll}
\hline Samples & $\mathrm{Ca}(\%)$ & $\mathrm{Cu}(\%)$ & $\mathrm{Fe}(\%)$ & $\mathrm{Mn}(\%)$ & $\mathrm{Zn}(\%)$ & $\mathrm{P}(\%)$ \\
\hline Feed 1 & $1.70 \pm 0.002$ & $0.0029 \pm 3 \times 10^{-5}$ & $0.039 \pm 4 \times 10^{-3}$ & $0.0049 \pm 5 \times 10^{-5}$ & $0.019 \pm 2 \times 10^{-4}$ & $1.47 \pm 0.01$ \\
Feed 2 & $5.30 \pm 0.06$ & $0.0049 \pm 5 \times 10^{-5}$ & $0.09 \pm 5 \times 10^{-3}$ & $0.092 \pm 9 \times 10^{-4}$ & $0.032 \pm 4 \times 10^{-4}$ & $3 ., 04 \pm 0.02$ \\
Feed 3 & $5.52 \pm 0.05$ & $0.0048 \pm 1.10^{-5}$ & $0.07 \pm 8 \times 10^{-4}$ & $0.081 \pm 8 \times 10^{-4}$ & $0.031 \pm 4 \times 10^{-4}$ & $3.01 \pm 0.04$ \\
Feed 4 & $1.57 \pm 0.03$ & $0.0019 \pm 1 \times 10^{-5}$ & $0.05 \pm 6 \times 10^{-4}$ & $0.052 \pm 7 \times 10^{-4}$ & $0.020 \pm 4 \times 10^{-4}$ & $1.50 \pm 0.02$ \\
Feed 5 & $1.22 \pm 0.02$ & $0.0028 \pm 3 \times 10^{-5}$ & $0.031 \pm 3 \times 10^{-4}$ & $0.019 \pm 2 \times 10^{-4}$ & $0.039 \pm 4 \times 10^{-4}$ & $1.03 \pm 0.03$ \\
Feces 1 & $1.81 \pm 0.01$ & $0.0019 \pm 2 \times 10^{-5}$ & $0.028 \pm 3 \times 10^{-3}$ & $0.0041 \pm 4 \times 10^{-5}$ & $0.018 \pm 2 \times 10^{-4}$ & $1.38 \pm 0.02$ \\
Feces 2 & $6.64 \pm 0.14$ & $0.0039 \pm 4 \times 10^{-5}$ & $0.091 \pm 9 \times 10^{-4}$ & $0.072 \pm 7 \times 10^{-4}$ & $0.012 \pm 3 \times 10^{-4}$ & $3.11 \pm 0.03$ \\
Feces 3 & $6.18 \pm 0.12$ & $0.0028 \pm 3 \times 10^{-5}$ & $0.052 \pm 6 \times 10^{-4}$ & $0.058 \pm 6 \times 10^{-4}$ & $0.041 \pm 5 \times 10^{-4}$ & $3.05 \pm 0.03$ \\
Feces 4 & $1.84 \pm 0.03$ & $0.0027 \pm 3 \times 10^{-5}$ & $0.056 \pm 7 \times 10^{-4}$ & $0.061 \pm 7 \times 10^{-4}$ & $0.029 \pm 3 \times 10^{-4}$ & $1.76 \pm 0.03$ \\
Feces 5 & $1.37 \pm 0.02$ & $0.0038 \pm 2 \times 10^{-5}$ & $0.021 \pm 4 \times 10^{-4}$ & $0.011 \pm 1 \times 10^{-4}$ & $0.030 \pm 3 \times 10^{-4}$ & $1.19 \pm 0.02$ \\
RM 1548a & $0.18 \pm 7 \times 10^{-3}$ & $2.29 \pm 0.04$ & $0.0032 \pm 7 \times 10^{-5}$ & $0.0006 \pm 1 \times 10^{-5}$ & $0.0023 \pm 6 \times 10^{-5}$ & $0.34 \pm 9 \times 10^{-3}$ \\
\hline
\end{tabular}

Feed 1 feed reference, Feed 2 feed with $30 \%$ yeast integrity, Feed 3 feed with $30 \%$ autolyzed yeast, Feed 4 feed with $25 \%$ bran turnip, feed with $10 \%$ jatropha, Feces 1 fish fed base diet, Feces 2 fish fed diets containing whole yeast, Feces fish fed diets containing autolyzed yeast, Feces 4 fish fed diets containing $25 \%$ turnip bran, Feces 5 fish fed diets containing $10 \%$ jatropha

\# Standard certificate containing: Ca-0.19 $\pm 0.01(\%) ; 2.32 \pm 0.16-\mathrm{Cu}\left(\mathrm{mg} \mathrm{kg}^{-1}\right)$; Fe-0.0035 $\pm 4.10^{-4}(5) ; 0.0006 \pm 1.7 .10^{-5}-\mathrm{Mn}(\%)$; Zn$0.0024 \pm 1.8 .10^{-4} ; \mathrm{P}-0.35 \pm 0.02$

Tables 2 and 3 reveal the close correspondence between the mineral concentrations measured in the samples of feed and feces. An analysis of the results of the determination of the nutrients summarized in Tables 2 and 3 indicates that the results obtained by ultrasonic extraction are consistent with those obtained by acid digestion. The calculated values of the standard deviations of all the results were low, showing relative standard deviations of $<3 \%$, which confirms the good repeatability of the measures and, hence, the good precision of the methods used. However, it should be noted that the proposed methodology (ultrasonic extraction) reduced the analytical time considerably, thus favoring the analytical speed. The accuracy of the extraction method was evaluated by determining the concentration of the minerals in a certified standard RM 1548a. The results of mineral analysis in the certified standard indicates that, using the ultrasound agitation, in addition to the fact that the values present relative standard deviations of $<2 \%$ for all minerals, which characterizes good repeatability and/or precision between the measures, thus proving the accuracy of the proposed extraction method. The apparent digestibility coefficients $(\mathrm{Da})$ of the nutrients in the feeds were calculated from Eq. (1) [12-14] using the results listed in Tables 2 and 3 and the percentage of chromium oxide (Table 4) [11]. The results from the calculations of Da obtained by acid mineralization and ultrasonic agitation are summarized in Tables 5 and 6.

Tables 5 and 6 list the Da values determined from extraction by acid mineralization and ultrasonic agitation, respectively, of the samples; the low (i.e., $<2 \%$ ) relative standard deviations are indicative of the excellent repeatability of the measurements and hence, the good precision of the proposed method.

A comparison of the values of $\mathrm{Da}$ of the minerals in the five feed samples used in the diet of Nile tilapia juveniles, shown in Tables 5 and 6, indicates that the values determined by the ultrasound agitation method are in agreement with the values obtained by acid mineralization of the samples. The latter method is the one normally employed in digestibility studies in fish nutrition [14-16]. All the calculated values presented relative standard deviations of $<2 \%$, demonstrating the good repeatability and hence, the

Table 4 Percentage of chromium oxide in particular feed and feces samples, as obtained from sampling and quantification in suspension by GFAAS

\begin{tabular}{ll}
\hline Samples & Percentage of chromium oxide \\
\hline Feed 1 & $0.10 \pm 0.0012$ \\
Feed 2 & $0.11 \pm 0.0013$ \\
Feed 3 & $0.09 \pm 0.0010$ \\
Feed 4 & $0.10 \pm 0.0010$ \\
Feed 5 & $0.12 \pm 0.0011$ \\
Feces 1 & $0.29 \pm 0.0037$ \\
Feces 2 & $0.30 \pm 0.0038$ \\
Feces 3 & $0.30 \pm 0.0030$ \\
Feces 4 & $0.31 \pm 0.0035$ \\
Feces 5 & $0.32 \pm 0.0036$
\end{tabular}

Feed 1 feed reference, Feed 2 feed with $30 \%$ yeast integrity, Feed 3 feed with $30 \%$ autolyzed yeast, Feed 4 feed with $25 \%$ bran turnip, feed with $10 \%$ jatropha, Feces 1 fish fed base diet, Feces 2 fish fed diets containing whole yeast, Feces 3 fish fed diets containing autolyzed yeast, Feces 4 fish fed diets containing $25 \%$ turnip bran, Feces 5 fish fed diets containing $10 \%$ jatropha 
Table 5 Coefficient of digestibility of specified minerals in the feed diets of Nile tilapia, for extraction via acid mineralization

\begin{tabular}{lllllll}
\hline Samples & $\mathrm{Ca}(\mathrm{Da}-\%)$ & $\mathrm{Cu}(\mathrm{Da}-\%)$ & $\mathrm{Fe}(\mathrm{Da}-\%)$ & $\mathrm{Mn}(\mathrm{Da}-\%)$ & $\mathrm{Zn}(\mathrm{Da}-\%)$ & $\mathrm{P}(\mathrm{Da}-\%)$ \\
\hline Feed 1 & $65.32 \pm 0.72$ & $77.33 \pm 0.85$ & $74.50 \pm 0.80$ & $72.80 \pm 0.80$ & $66.00 \pm 0.70$ & $68.30 \pm 0.75$ \\
Feed 2 & $52.72 \pm 0.55$ & $70.40 \pm 0.74$ & $64.21 \pm 0.73$ & $71.22 \pm 0.76$ & $87.66 \pm 0.94$ & $62.30 \pm 0.67$ \\
Feed 3 & $64.25 \pm 0.74$ & $82.00 \pm 1.04$ & $70.00 \pm 0.87$ & $77.50 \pm 1.19$ & $60.00 \pm 0.74$ & $68.80 \pm 0.78$ \\
Feed 4 & $62.04 \pm 0.82$ & $52.00 \pm 0.58$ & $62.70 \pm 0.76$ & $61.60 \pm 0.76$ & $52.00 \pm 0.57$ & $62.14 \pm 0.73$ \\
Feed 5 & $59.06 \pm 0.73$ & $52.00 \pm 0.61$ & $76.00 \pm 0.91$ & $81.00 \pm 1.07$ & $73.00 \pm 0.91$ & $56.90 \pm 0.69$ \\
\hline
\end{tabular}

Feed 1 feed reference, Feed 2 feed with $30 \%$ yeast integrity, Feed 3 feed with $30 \%$ autolyzed yeast, Feed 4 feed with $25 \%$ bran turnip, feed with $10 \%$ jatropha

\begin{tabular}{lllllll}
\hline Samples & $\mathrm{Ca}(\mathrm{Da}-\%)$ & $\mathrm{Cu}(\mathrm{Da}-\%)$ & $\mathrm{Fe}(\mathrm{Da}-\%)$ & $\mathrm{Mn}(\mathrm{Da}-\%)$ & $\mathrm{Zn}(\mathrm{Da}-\%)$ & $\mathrm{P}(\mathrm{Da}-\%)$ \\
\hline Feed 1 & $63.80 \pm 0.70$ & $77.72 \pm 0.87$ & $75.60 \pm 0.84$ & $71.55 \pm 0.81$ & $67.80 \pm 0.71$ & $68.10 \pm 0.75$ \\
Feed 2 & $54.40 \pm 0.65$ & $70.55 \pm 0.80$ & $62.60 \pm 0.71$ & $71.04 \pm 0.78$ & $86.12 \pm 0.92$ & $62.15 \pm 0.67$ \\
Feed 3 & $61.93 \pm 0.75$ & $82.50 \pm 0.96$ & $68.80 \pm 0.82$ & $78.51 \pm 0.82$ & $60.32 \pm 0.74$ & $69.60 \pm 0.70$ \\
Feed 4 & $60.15 \pm 0.67$ & $54.53 \pm 0.65$ & $64.16 \pm 0.71$ & $62.46 \pm 0.74$ & $53.60 \pm 0.61$ & $62.45 \pm 0.66$ \\
Feed 5 & $61.82 \pm 0.70$ & $51.14 \pm 0.62$ & $75.61 \pm 0.94$ & $79.15 \pm 0.83$ & $72.30 \pm 0.81$ & $58.40 \pm 0.73$ \\
\hline
\end{tabular}

Feed 1 feed Reference, Feed 2 feed with $30 \%$ yeast integrity, Feed 3 feed with $30 \%$ autolyzed yeast, Feed 4 feed with $25 \%$ bran turnip, feed with $10 \%$ jatropha
Table 6 Coefficient of digestibility of specified minerals in the feed diets of Nile tilapia, for extraction via ultrasonic agitation
2. D.M. Gatlin III., F.T. Barrows, P. Brown, K. Dabrowski, T.G. Gaylord, R.W. Hardy, E. Herman, G. Hu, G. Hu, Å. Krogdahl, R. Nelson, K. Overturf, M. Rust, W. Sealey, D. Skonberg, E.J. Souza, D. Stone, R. Wilson, E. Wurtele, A. USDA, Aquac. Res. 38(6), 551-579 (2007)

3. D. Thiessen, Optimization of feed peas, canola and flaxseed for aqua feeds: the Canadian Prairie perspective, ed. by S. Cruz et al. Avances In Nutrición Acuicola VII. Memorias del VII Simposium Internacional de nuricion acuicula, (Hermosillo, Sonora, México, 2004), pp. 16-19

4. M. Higuera, Diseños y métodos experimentales de evaluación de dietas, in By (Nutrición en Acuicultura II, ed. by J.A.E. Monteros, M. Labarta (Comisión Asesora de Investigación Científica y Técnica, Madrid, 1987), pp. 291-318

5. National Research Council (NRC), Nutrient requirements of fish (National Academy Press, Washington, DC, 1993), p. 115

6. F.A. Silva, R.C.F. Neves, L.G. Quintero-Pinto, C.C.F. Padilha, S.M.A. Jorge, M.M. Barros, L.E. Pezzato, P.M. Padilha, Chemosphere 68(8), 1542-1547 (2007)

7. M.A.D. Bonfim, E.A.T. Lanna, Revis. Eletrôn. Nutr. 1(1), 3 (2004)

8. H. Bremer Neto, G.C.A. Fessel, L.E. Pezzato, Ciênc. Rural 35, 3 (2005)

9. Cookbook Shimadzu, Operation Manual: Atomic Absorption Spectrophotometer AA-6800, SHIMADZU, (2000)

10. G.S. Gonçalves, L.E. Pezzato, P.D.M. PADILHA, M.M. Barros, Braz. J Anim. Sci. 36(5), 1473-1480 (2007)

11. F.A. Silva, C.C.F. Padilha, L.E. Pezzato, M.M. Barros, P.M. Padilha, Talanta 69(4), 1025-1030 (2006)

12. W.M. Furuya, L.E. Pezzato, A.C. Pezzato, M.M. Barros, E.C. Miranda, Rev. Bras. de Zootec. 30, 1143-1149 (2001)

13. A.C. Pezzato, Rev. Bras. de Zootec. 31, 1595-1604 (2002)

14. M.V.C. Sá, L.E. Pezzato, M.M. Barros, P.M. Padilha, Aquaculture 238, 385-401 (2004)

15. M.V.C. Sá, L.E. Pezzato, M.M. Barros, P.M. Padilha, J. World Aquac. Soc., 36(3), 380-388 (2005)

16. M.V.C. Sá, L.E. Pezzato, M.M. Barros, P.M. Padilha, Aquac. Nutr., 11(1), 273-281 (2005)

\section{References}
1. FAO, ORGANIZACION DE LAS NACIONES UNIDAS PARA LA AGRICULTURA Y LA ALIMENTACIÓN (2006)

